\title{
FIRE RESISTANCE OF ENERGY EFFICIENT FLOOR STRUCTURES
}

\author{
Meri Cvetkovska $^{\mathrm{a}}$, Milivoje Milanovic ${ }^{\mathrm{b}}$, Marijana Lazarevska ${ }^{\mathrm{a}}$, Ana Trombeva Gavriloska ${ }^{\mathrm{c}}$ \\ ${ }^{\text {a }}$ Ss. Cyril and Methodius University, Faculty of Civil Engineering, Skopje, Macedonia \\ ${ }^{\mathrm{b}}$ State University of Novi Pazar, Department of Technical Sciences, Novi Pazar, Serbia \\ ${ }^{\mathrm{c}}$ Ss. Cyril and Methodius University, Faculty of Architecture, Skopje, Macedonia
}

\begin{abstract}
This paper presents the numerically achieved results for the fire resistance of several types of floor structures which are mostly used in our residential and rural buildings and in same time fulfil the energy efficient criteria, as: semi-prefabricated reinforced concrete slabs system FERT and STIRODOM (with infill of extruded polystyrene -XPS), timber-concrete composite floor structure and traditional timber floor structure. The solid RC slab was analysed only for comparison. Using the computer programs SAFIR, the effect of the intensity of the permanent and variable actions and the effect of the thermal isolation on the fire resistance of simply supported slabs were analyzed. The fire resistance was defined with respect to the criteria of usability of the structures in fire conditions, according to Eurocodes and the standards in force.
\end{abstract}

Keywords: energy efficiency, floor structures, heat transfer, fire resistance

\section{INTRODUCTION}

Floor structures, as horizontal elements, have a very important role in providing bearing capacity, usability and stability of the building as a whole. Their proper selection and design, when they are exposed to different types of loads (mainly: permanent and variable), should provide stable and safe structure during the exploitation period.

In case of fire floor structures do not have only load bearing function. In most cases they are used as elements for separating the fire compartment. Where compartmentation is required, the elements forming the boundaries of the fire compartment, including joints, shall be designed and constructed in such a way that they maintain their separating function during the relevant fire exposure (EN 1991-1-2, 2004). This shall ensure, where relevant, that integrity failure does not occur, insulation failure does not occur, thermal radiation from the unexposed side is limited.

Does the floor structure meet the required fire resistance criteria mainly depends on: mechanical and thermal characteristics of the materials used for the construction; initial loading level; support conditions; dimensions of the cross section and the fire scenario.

The fire resistance of the most frequently used floor structures in the multi story residential buildings and in one or two storey individual housing constructions, as well as floor structures mostly used in rural buildings, was analyzed and the results are presented in this paper. All six types of floor structures were treated as simply supported slabs.

\section{FIRE RESISTANCE OF SEMI-PREFABRICATED REINFORCED CONCRETE FLOOR STRUCTURES}

Mainly, the massive simply supported or continuous reinforced concrete slabs with different thickness are used for the multi story residential buildings. For the individual housing construction semi-prefabricated reinforced concrete slabs system FERT and STIRODOM (with infill of extruded polystyrene-XPS) are usually used. These types of slabs have load bearing capacity only in one direction and from that reason only simply supported slabs are analyzed in this paper. The RC slabs and the slabs system STIRODOM were constructed with and without thermal insulation at the bottom side of the slabs. In fire conditions, as a result of a large number of real fire tests and corresponding numerical analyzes, it was found out that the moment of failure of the floor structure is always followed by significant deformation (deflection). If the structure is close to the limit state, 
after the cooling phase the residual deflections are so great that it cannot be used without significant rehabilitation. For these reasons, during the fire action, the deformation (deflection) of the slab is limited to prescribed value. According to the ISO standard, this limit value is L/30 (L is the span of the slab).

For defining the fire resistance of the floor structures, the proper thermal characteristics of the applied materials should be taken into account. Comparing with the traditional one, the new contemporary materials are lightweight and have better thermal and acoustic properties, but it doesn't mean that in case of fire the higher fire resistance should be achieved. Some of these materials (Styrodur, Styrofoam, etc) are thermally unstable when exposed to high temperatures.

The cross sections and the dimensions of the three different types of simply supported floor structures were defined according to the current standards and the technical characteristics of the producers (Figure 1). The following parameters, characteristics and conditions were assumed:

- The slabs were exposed to ISO 834 Standard fire only from the bottom side,

- A separate stripes with dimensions: $b=1 \mathrm{~m}, \mathrm{~L}=6 \mathrm{~m}$ (typical section) were analyzed,

- The temperature dependent physical and mechanical properties of the siliceous aggregate concrete (compressive strength $\mathrm{f}_{\mathrm{c}}=30 \mathrm{Mpa}$ ) and the reinforcement (yield strength $\mathrm{f}_{\mathrm{y}}=400 \mathrm{Mpa}$ ) were assumed according to EC2, part 1-2,

- Physical properties of other materials at ambient temperature were taken according to the values provided by the producers and are given in Table 1.

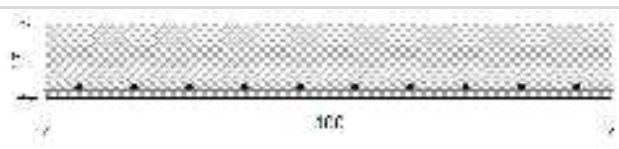

a)

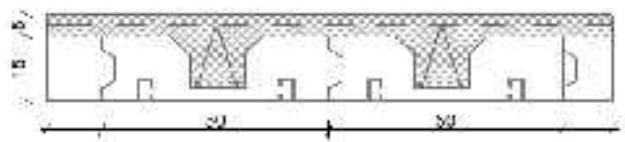

c)

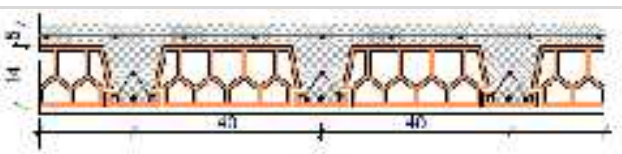

b)

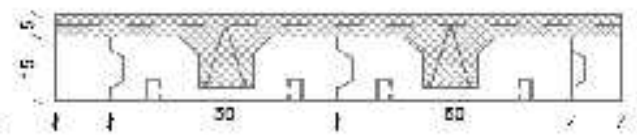

d)

Fig. 1 Different types of floor structures: a) RC slab; b) slab system FERT; c) slab system STIRODOM with plasterboard as thermal insulation; d) slab system STIRODOM

Table 1 Thermal properties of insulation materials

\begin{tabular}{|c|c|c|c|c|c|c|}
\hline \multicolumn{2}{|c|}{ Properties/material } & brick & Plasterboard & EPS & Concrete & Reinforcement \\
\hline Density & $\mathrm{kg} / \mathrm{m}^{3}$ & 1500 & 1000 & 30 & 2400 & 7800 \\
\hline thermal conductivity & $\mathrm{W} / \mathrm{mK}$ & 0.80 & 0.21 & 0.035 & 2.0 & 54 \\
\hline specific heat & $\mathrm{J} / \mathrm{kgK}$ & 920 & 1090 & 1450 & 960 & 440 \\
\hline Surface emissivity & & 0.93 & 0.85 & 0.90 & 0.92 & 0.69 \\
\hline
\end{tabular}

For all types of floor structures the design loads (permanent and variable) at ambient temperatures were assumed to be the loads that cause vertical deformation equal to L/250 (EN 1992-1, 2004). These loads were considerably lower than the ultimate loads. For the selected types of floor structures the fire resistance in time domain is presented in Figure 2. The design loads that, at ambient temperatures, cause vertical deformation equal to L/250 are taken as $100 \%$. All other loads are given as a percentage of these limited design loads $(84 \%, 67 \%$ and $50 \%)$. Differences in the fire resistance of the certain types of floor structures are not significant except for the slab system STYRODOM with ceiling of plasterboard. This type of floor structure is more resistant to the effects of temperature and the fire resistance is much higher than for the other types of floor structures. The same structure, but without plasterboard at the bottom (ceiling) side (only thin plaster layer), has the lowest fire resistance. The reason for that is the melting of the infill of extruded polystyrene-XPS caused by temperatures over $\mathrm{T}=300^{\circ} \mathrm{C}$. At temperatures $\mathrm{T}=450-500^{\circ} \mathrm{C}$ the infill is completely burned and the temperatures in the cross section of the slab are much higher 
than in other three cases. Consequently, the deflection rapidly increases much more over the limited value $\mathrm{L} / 30$.

Time dependant bending deformations (deflections) of the analyzed floor structures are presented in Figure 3. As a result of the excellent insulation properties of the plasterboard lining, the slab system STYRODOM with plasterboard at the bottom side has the highest fire resistance and smallest vertical deflection. During the heating period $t=60 \mathrm{~min}$, as a result of the initial stiffness, the STYRODOM slab without plasterboard has small initial deflection, but after this time period, as a result of melting of the infill, the bending deformation (deflection) rapidly increases and after $\mathrm{t}=70$ min reaches the limited value L/30. When fire exposure is less than $40 \mathrm{~min}$ the $\mathrm{RC}$ slab has higher stiffness and lower deflection then the slab system FERT. The thermal conductivity of concrete is twice higher than of the brick, respectively the temperatures in the cross section of the RC slab are higher then of the slab system FERT, respectively the stiffness of the RC slab decreases faster and after $\mathrm{t}=90$ min both structures simultaneously reach the limited deflection L/30 (Figure 3).

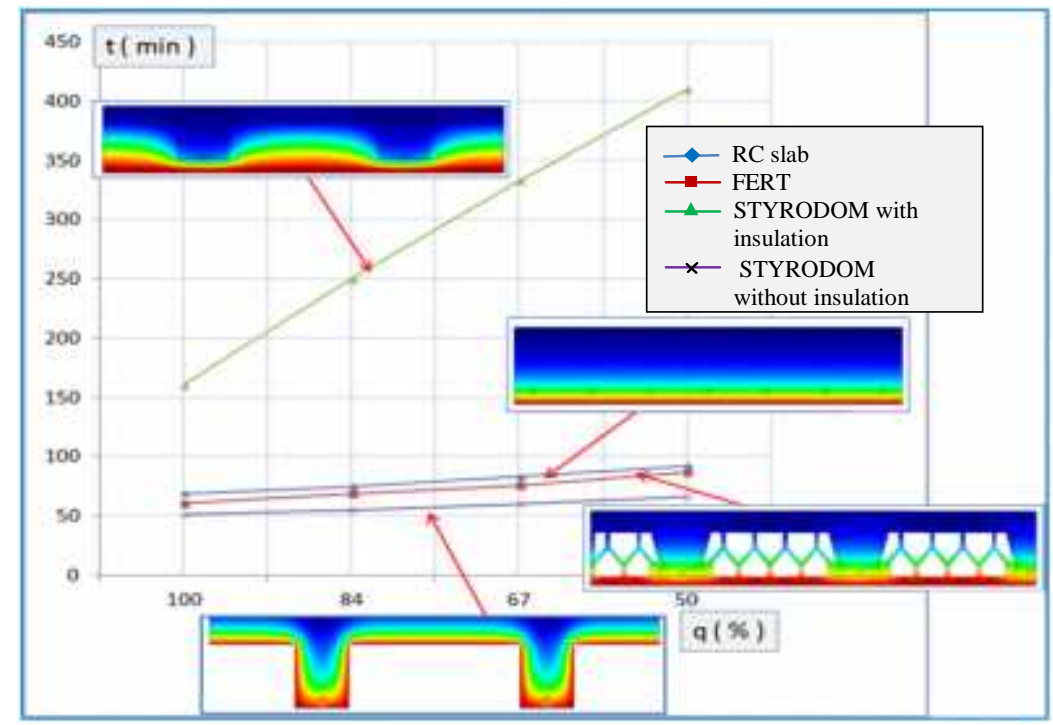

Fig. 2 Fire resistance of different types of simply supported floor structures, as function of the applied loads expressed as percentage of the design loads that cause deflections L/250

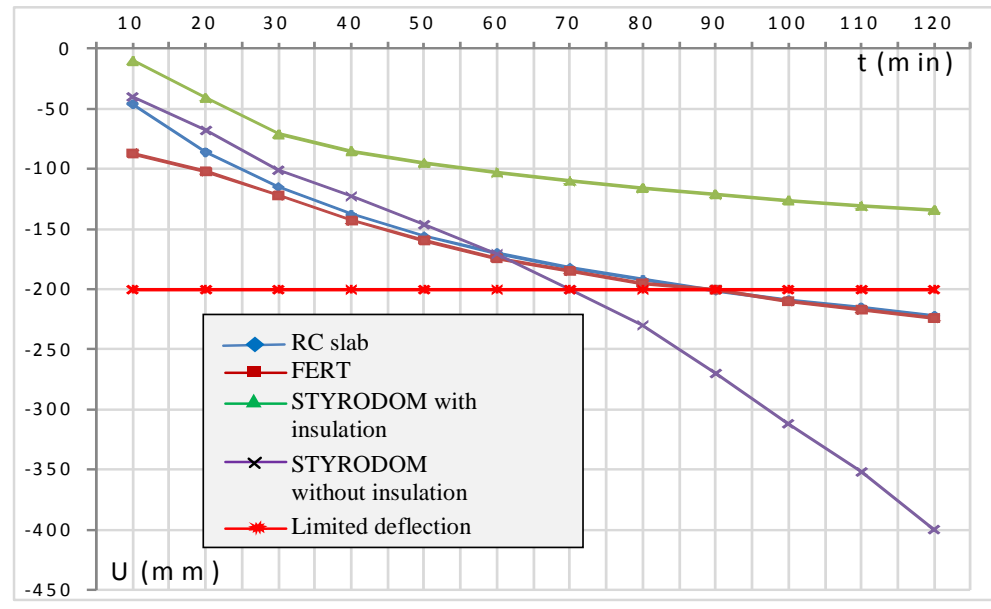

Fig. 3 Time dependent vertical deflections of different types of simply supported floor structures exposed to fire from the bottom side

The analysis presented in this paper show that from all three types of floor structures the RC slabs have the best performance at ambient temperature, as well as in case of fire. The performance of the slab system FERT when exposed to fire is satisfactory too, but we should not neglect its lower stiffness and greater deflections at ambient temperatures. The fire resistance of the contemporary floor structures (STYRODOM, ITONG, etc.) depends on the thermal insulation of the slab. The 
infill of extruded polystyrene-XPS is sensitive on temperatures over $300^{\circ} \mathrm{C}$, therefore we should no avoid these structures, but it is necessary to provide protective measures.

\section{FIRE RESISTANCE OF TIMBER BASED FLOOR STRUCTURES}

The timber floor is widely used in traditional and rural buildings, but the high combustibility of the wood results in low fire resistance of this type of floors. Wood can be protected by fire protective claddings, other protection materials or by other structural members and nowadays a special attention is paid to this problem. One of the possible solutions for increasing the fire resistance of wooden floor structures is the composite timber-concrete floor assembly made of timber girders and reinforced concrete slab, while the cavities are field with mineral or rock wool. Two types of floor structures, timber-concrete composite floor structure TCCFS and traditional timber floor structure TFS, for two different fire scenarios, are analysed in this paper.

The cross sections and the dimensions of the two different types of simply supported floor structures with span $\mathrm{L}=5 \mathrm{~m}$ were defined according to the current standards and are presented on Figure 4. Material properties at room temperatures are given in Table 2. The temperature dependent physical and mechanical properties of the siliceous aggregate concrete (compressive strength $\mathrm{f}_{\mathrm{c}}=30 \mathrm{Mpa}$ ) and the reinforcement (yield strength $\mathrm{f}_{\mathrm{y}}=400 \mathrm{Mpa}$ ) were assumed according to EN 1992 1-2. For standard fire exposure, values of thermal conductivity, specific heat and the ratio of density of softwood were taken as given in EN 1995-1-2. The thermal conductivity values of the char layer are apparent values rather than measured values of charcoal, in order to take into account increased heat transfer due to shrinkage cracks above $500^{\circ} \mathrm{C}$ and the consumption of the char layer at about $1000^{\circ} \mathrm{C}$ (Figure 5). Cracks in the charcoal increase heat transfer due to radiation and convection. The computer program SAFIR does not take into account these effects.

Each type of floor structure was analyzed for two different types of ceiling: lime cement mortar $2 \mathrm{~cm}$ or gypsum plasterboard $2 \mathrm{~cm}$, and for two different positions of the fire action, at the top and at the bottom side of the floor:

- Case 1: TFS with ceiling made of lime cement mortar, fire at the top side

- Case 2: TFS with ceiling made of gypsum plasterboard, fire at the bottom side

- Case 3: TFS with ceiling made of lime cement mortar, fire at the bottom side

- Case 4: TCCFS with ceiling made of gypsum plasterboard, fire at the bottom side

- Case 5: TCCFS with ceiling made of lime cement mortar, fire at the bottom side

- Case 6: TCCFS with ceiling made of lime cement mortar, fire at the top side.
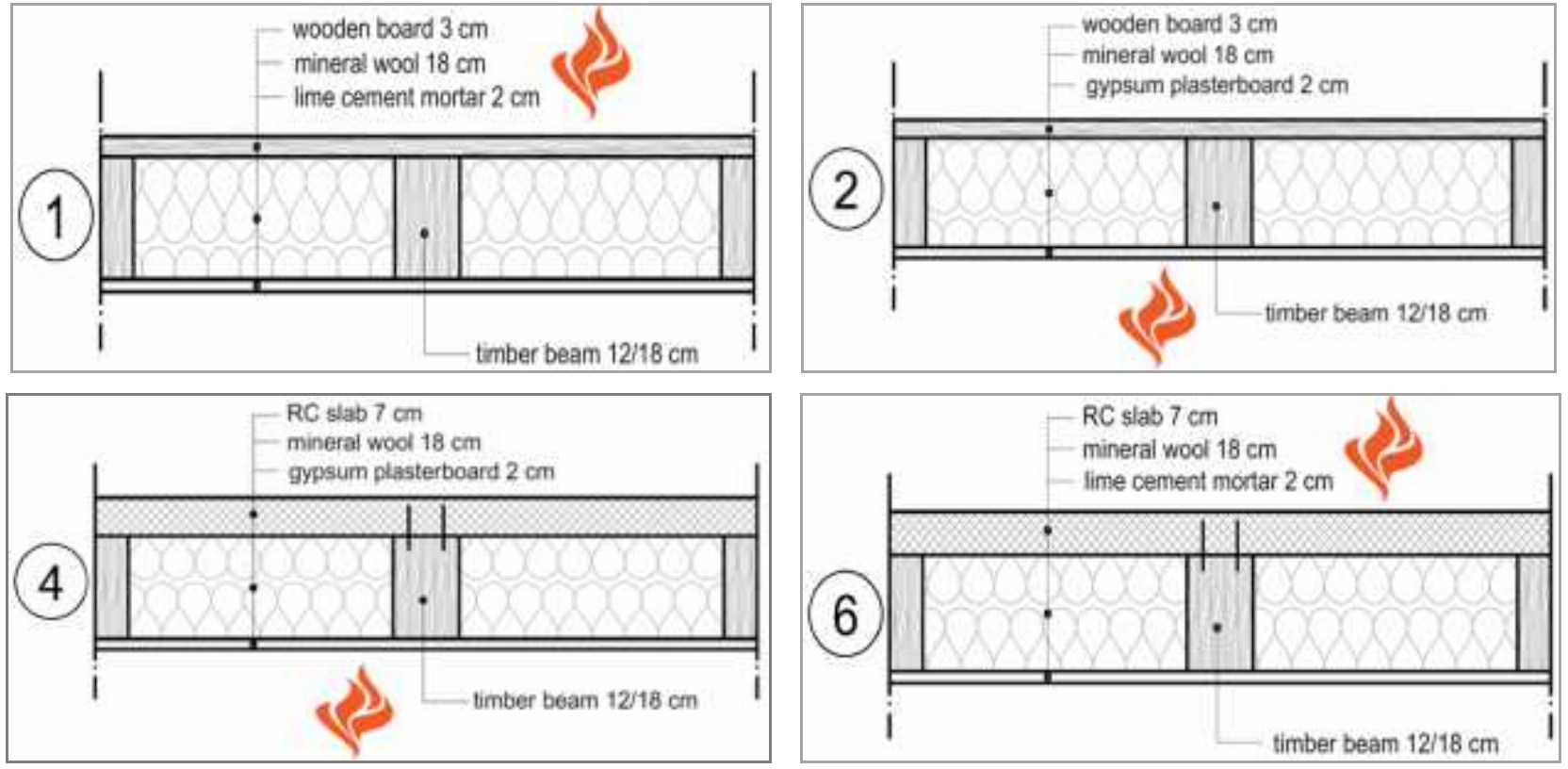

Fig. 4 The cross sections and the dimensions of the two different types of simply supported floor structures with specified position of the fire action 
Table 2 Material properties of composite materials at room temperatures

\begin{tabular}{|l|l|c|c|c|c|c|}
\hline Material properties & & Concrete & Wood & Gypsum & mortar & Miner. wool \\
\hline specific mass & $\mathrm{kg} / \mathrm{m}^{3}$ & 2400 & 450 & 900 & 1850 & 150 \\
\hline water percentage & $\%$ & 8 & 4 & 4 & 8 & 2 \\
\hline convection coeff. on hot side & $\mathrm{W} / \mathrm{m}^{2} \mathrm{~K}$ & 25 & 25 & 25 & 25 & 25 \\
\hline convection coeff. on cold side & $\mathrm{W} / \mathrm{m}^{2} \mathrm{~K}$ & 9 & 9 & 9 & 9 & 9 \\
\hline relative emissivity & - & 0,8 & 0,8 & 0,85 & 0,8 & 0,85 \\
\hline specific Heat & $\mathrm{J} / \mathrm{kgK}$ & $900^{*}$ & $1530^{*}$ & 1090 & 400 & 150 \\
\hline thermal conductivity & $\mathrm{W} / \mathrm{mK}$ & $1,6^{*}$ & $0,12^{*}$ & 0,21 & 0,87 & 0,035 \\
\hline
\end{tabular}

* The values for the specific heat and the thermal conductivity of concrete and wood are temperature dependent and only the initial values are given $\left(\mathrm{T}=20^{\circ} \mathrm{C}\right)$. Reductions of the values at higher temperatures are as it is recommended in EN 1992-1-2 and EN 1995-1-2.

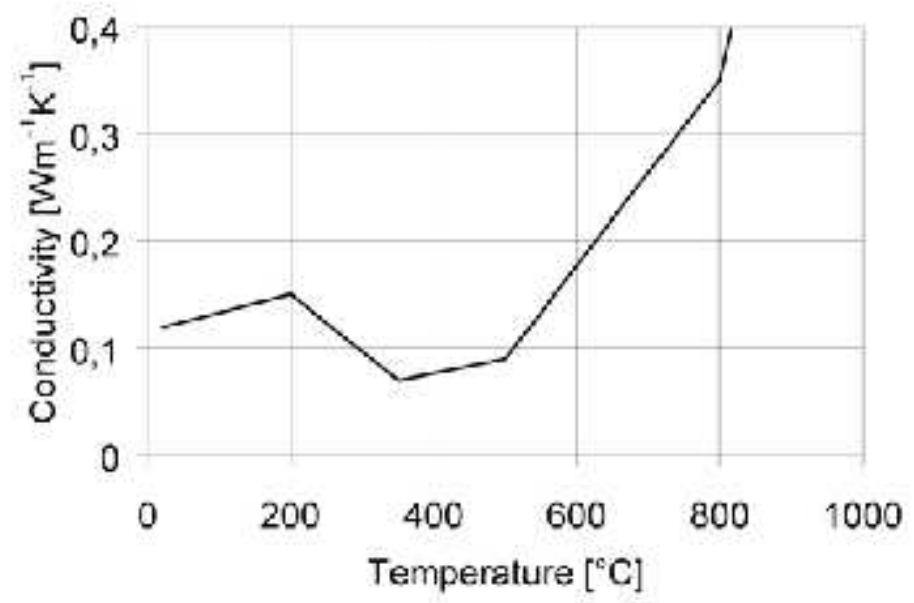

Fig. 5 Temperature-thermal conductivity relationship for wood and the char layer, according to EN 1995-1-2

Numerically achieved results for the temperature distribution in the cross section of timber-concrete composite floor structure with gypsum plasterboard ceiling, for different position of the fire, are presented on Figure 6.
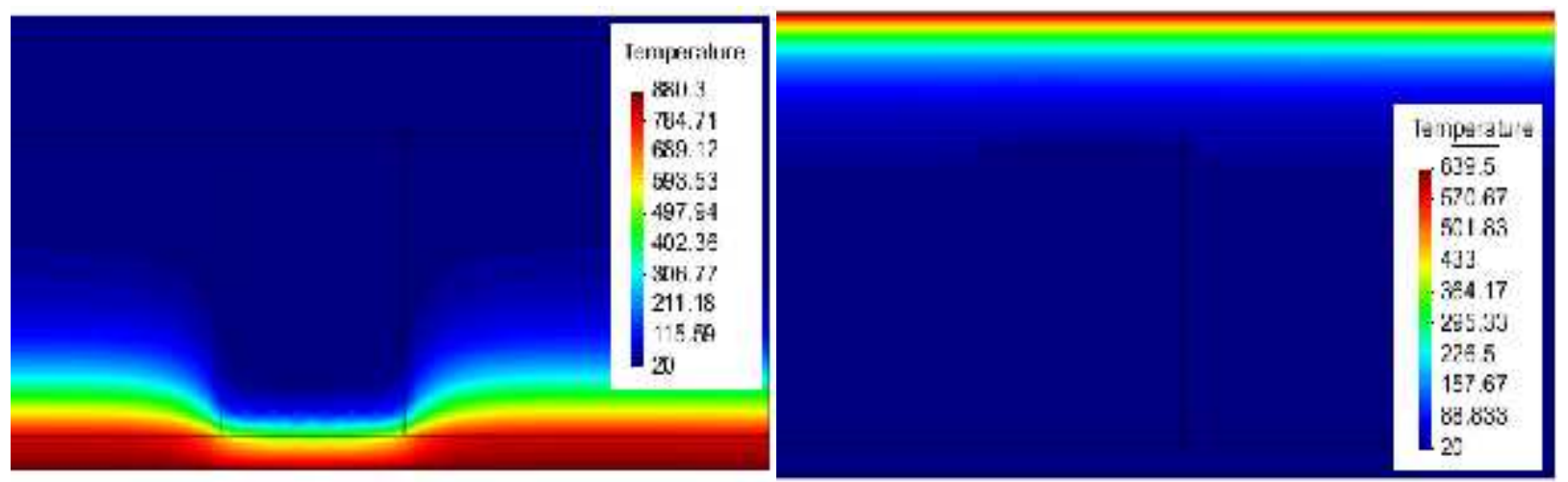

Fig. 6 Temperature distribution in the cross section of timber-concrete composite floor structure with gypsum plasterboard ceiling, at the moment of failure (when $\mathrm{q}_{\mathrm{fi}} / \mathrm{q}_{\mathrm{u}}=0.8$ )

a) case 4-fire from the bottom side, $\mathrm{t}=2410 \mathrm{sec}$.; $\mathrm{b}$ ) case 6 -fire from the top side, $\mathrm{t}=1080 \mathrm{sec}$.

The analysis presented in this paper show that from all six cases, the timber-concrete composite floor structure with ceiling made of gypsum plasterboard and exposed to fire from the bottom side has the best performance (Figure 7). The gypsum plasterboard ceiling and the rock wool infill have an insulating function and provide lower temperatures in the cross section of the floor assembly (Figure 6a). When the fire is from the top side of the thin concrete slab $(\mathrm{d}=7 \mathrm{~cm})$, in short time period the temperature penetrates dipper into the concrete slab (Figure 6b), the slab loses the bearing capacity and becomes a dead load for the timber girder, therefore the whole structure 
collapses. When the load coefficient $\mathrm{q}_{\mathrm{fi}} / \mathrm{q}_{\mathrm{u}}$ is increased, the fire resistance is decreased, but not proportionally to the value of the load coefficient, and this effect is mostly stressed in case 5.

The timber floor structure (case 1, 2 and 3) has much lower fire resistance that the timber-concrete composite floor structure. It is more expressed when the load coefficient $\mathrm{q}_{\mathrm{fi}} / \mathrm{q}_{\mathrm{u}}$ has expected values (less than 0.5). When fire is from the top side the char layer protects the timber girder from burning (low value of the thermal conductivity, Figure 5) and the girder keeps his original dimensions for a longer period than in case when the fire is from the bottom side.

For expected values of the load coefficient $\left(\mathrm{q}_{\mathrm{fi}} / \mathrm{q}_{\mathrm{u}}\right.$ less than 0.5$)$ and for the same fire scenario, the fire resistance of the timber concrete composite floor structure is almost twice higher than the fire resistance of the timber floor structure.

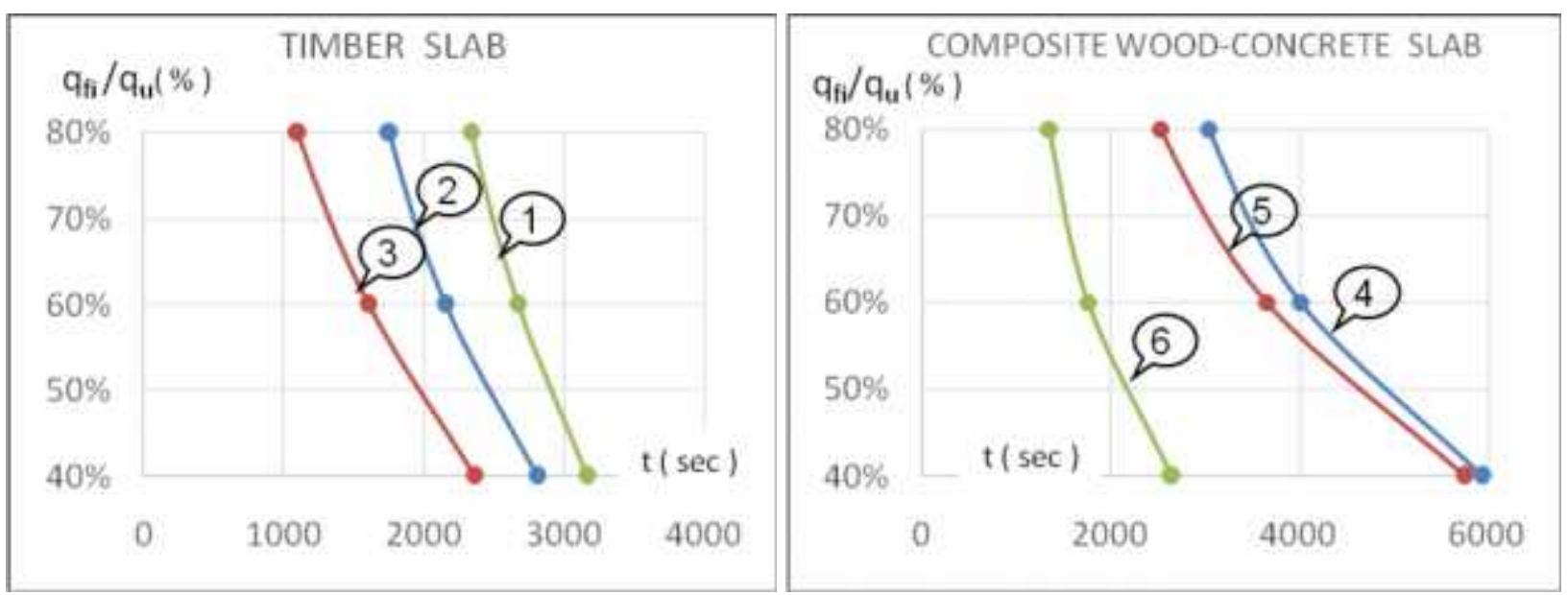

Fig. 7 The effect of the intensity of the permanent action and the position of the ISO 834 standard fire on the fire resistance of the two types of simply supported floor structures

\section{REFERENCES}

EN 1991-1-2: Eurocode 1, part 1-2. 2002. Actions on structures - Part 1-2: General rules. Actions on structures exposed to fire

EN 1992-1-2: Eurocode 2, part 1-2. 2004. Design of concrete structures - Part 1-2: General rules. Structural fire design

EN 1995-1-2: Eurocode 5, part 1-2. 2004. Design of timber structures - Part 1-2: General rules. Structural fire design

SAFIR. 2014. Computer program, University of Liege, Belgium 